\title{
Inovação, tradição, historiografia: um breve diálogo com Javier Fernández Sebastián
}

Innovation, tradition, historiography: a brief dialogue with Javier Fernández Sebastián

\section{Fábio Franzini \\ Professor no Departamento de História da Universidade Federal de São Paulo (EFLCH/Unifesp - Guarulhos/Brasil) \\ E-mail: fabio.ff.franzini@gmail.com}

\section{Resumo}

Este artigo pretende apresentar comentários pontuais aos argumentos centrais do texto "Tradiciones electivas. Cambio, continuidad y ruptura en historia intelectual", de Javier Fernández Sebastián. Espera-se, com isso, destacar a sua força analítica e, ao mesmo tempo, sugerir outros possiveis encaminhamentos para a discussão proposta.

\section{Abstract}

This article aims to present some short comments about the core arguments made by Javier Fernández Sebastián in his text "Tradiciones electivas. Cambio, continuidad y ruptura en historia intelectual". It intends to show the power of Fernández Sebastián's analysis as well as to suggest other possible approaches to the discussion proposed by the author.

Palavras-chave

Tradição, escrita da história, crítica historiográfica.

\section{Keywords}

Tradition, writing of history, historiographical critique. 
Se a tarefa não foi fácil, nem por isso deixou de ser prazerosa. Assim, agradeço muito aos colegas da Almanack pela gentileza do convite, em especial Andréa Slemian e João Paulo Garrido Pimenta, e pela oportunidade privilegiada de ouvir e debater com os Professores Javier Fernández Sebastián e Fernando Nicolazzi.

2

Apenas para ilustrar tal afinidade e concordância com a perspectiva de Fernández Sebastián, ainda que numa chave de leitura diferente, cf. FRANZINI, Fábio; GONTIJO, Rebeca. Memória e história da historiografia no Brasil: a invenção de uma moderna tradição, anos 1940-1960. In: SOIHET, Rachel; ALMEIDA, Maria Regina C. de; AZEVEDO, Cecilia; GONTIJO, Rebeca (orgs.). Mitos, projetos e práticas políticas. Memória e historiografia. Rio de Janeiro: Civilização Brasileira, 2009. p. 141-160.
3

É importante ressaltar que, se afirmações assim hoje não nos causam surpresa, isso não significa que os historiadores estejam todos de acordo com elas, nem que aqueles em concordância o estejam da mesma forma; muito ao contrário, seu conteúdo, em essência, expressa o ponto central de um grande, polêmico e muitas vezes apaixonado debate sobre o caráter e a legitimidade do nosso ofício, o qual já dura décadas e parece longe do fim. Cf., apenas como um entre inúmeros exemplos possiveis, GINZBURG, Carlo. Relações de força. História, retórica, prova. São Paulo: Companhia das Letras, 2002.
Duas razões tornam nada fácil a tarefa de comentar o artigo "Tradiciones electivas. Cambio, continuidad y ruptura en historia intelectual", de Javier Fernández Sebastián. ${ }^{1}$ A primeira delas deriva de sua clareza e precisão, que deixam poucas brechas para a inserção de uma cunha crítica, seja para fendê-lo, seja para lapidá-lo - ainda que nem um nem outro gesto, é bom dizer, estivesse no horizonte das minhas pretensões ao ser convidado para participar deste fórum. A segunda, de sua perspectiva analítica, com a qual tenho grande afinidade e coloco-me inteiramente de acordo, tanto no que diz respeito a buscar "a dimensão produtiva e dinâmica da tradição", num plano geral, quanto no que se refere aos esforços de se escapar aos modelos da "continuidade" e da "ruptura" no campo especifico da história intelectual. ${ }^{2}$

Diante disso, minha saída será explorar pontualmente a argumentação de Fernández Sebastián para, por meio desse breve diálogo, reforçar os aspectos que nela vejo como cruciais e, a partir daí, tentar indicar algumas implicações e desdobramentos possíveis. Penso, por um lado, naquilo que perpassa e fundamenta todo o texto: a crítica à antinomia supostamente existente entre "tradição" e "inovação", a qual possui, a meu ver, uma correspondência direta com o debate historiográfico contemporâneo; por outro, na proposta que apresenta para a superação teórico-metodológica dos modelos "exclusivos e excludentes" no estudo da relação entre "tradição" e "inovação", da qual decorre a formulação de uma categoria específica de análise, a de "tradições eletivas", cujo potencial é muito bem demonstrado nas páginas finais do artigo.

\section{1}

Embora situadas nos marcos de uma história político-intelectual, creio não ser necessário ressaltar que as questões e encaminhamentos apresentados por Javier Fernández Sebastián não se limitam aos códigos e práticas desse campo em sentido estrito, mas dizem respeito a desafios que nós, historiadores, temos enfrentado nas últimas décadas. Não por acaso, seu empenho em demonstrar o quão empobrecedoras são as visões dicotômicas das relações entre tradição e inovação, entre continuidade e mudança, encontra-se com outro debate corrente, este mais amplo, acerca das possibilidades e limites da escrita da história, o qual transparece em suas preocupações acerca dos atributos da representação historiográfica do passado. Trata-se, a rigor, de um encontro inevitável: de saída, porque suas reflexões surgem, como ele mesmo diz, de sua própria prática do ofício de historiador; depois, porque esta prática, por se exercer, evidentemente, no presente - neste presente -, não tem como deixar de reconhecer o impacto do linguistic turn sobre a historiografia. Justamente por isso, não nos soam nem um pouco impróprias ou surpreendentes afirmações como as seguintes:

Puesto que el pasado, como realidad factual, se ha desvanecido para siempre, toda interpretación historiográfica en cierto modo "recrea", reconstruye a partir de las fuentes una representación de las experiencias acontecidas y, en este sentido, se sirve de armas literarias no muy diferentes a las de la ficción. Al historiador le es necesario "fingir" realidades históricas desaparecidas produciendo retóricamente efectos de sentido; entre ellos, aquellos efectos que destacan lo que hay de tradicional o de innovador en los sucesos, situaciones o estructuras que inserta en su relato; en ese sentido el historiador se ve obligado a servirse de "ficciones perspectivistas", de recursos poéticos y de tropos. ${ }^{3}$ 
4

WHITE, Hayden. Teoria literária e escrita da história. Estudos Históricos, Rio de Janeiro, Vol. 7 , n. 13, 1994. p. 29. (grifos do autor).

5

WHITE, Hayden. Meta-história. A imaginação histórica do século XIX. 2. ed. São Paulo: Edusp, 1995. p. 11.
Ainda que Fernández Sebastián incorpore, na sequência, a crítica a nomes como Hayden White e Frank Ankersmit (que, como se sabe, têm discutido - por caminhos diferentes, cumpre observar - as dimensões linguístico-literárias que envolvem a "operação historiográfica") para ressaltar que o reconhecimento do uso de recursos figurativos pelo historiador não significa assumir a historiografia como "um mero artifício literário", seu texto, a meu ver, ecoa fortemente a importância e o valor do trabalho desses autores, assimilando muito de sua contribuição. Chama-me a atenção, em particular, a semelhança entre o tom do trecho supracitado - que, longe de esgotar-se em si mesmo, se repete em várias outros parágrafos do artigo - e a abordagem específica de White acerca da elaboração do discurso da história, apresentadas em formulações como:

\begin{abstract}
Na passagem do estudo de um arquivo para a composição de um discurso e para a sua tradução numa forma escrita, os historiadores têm de empregar as mesmas estratégias da figuração linguistica utilizadas por escritores imaginativos para dotar seus discursos daqueles tipos de significados latentes, secundários ou conotativos que requererão que suas obras não só sejam recebidas como mensagens, mas sejam lidas como estruturas simbólicas. 0 significado latente, secundário ou conotativo contido no discurso histórico é a sua interpretação dos eventos que constituem seu conteúdo manifesto. 0 tipo de interpretação tipicamente produzido pelo discurso histórico é o que dá àquilo que de outra forma permaneceria apenas uma série de eventos cronologicamente ordenados a coerência formal do tipo de estruturas-deenredo encontradas na ficção narrativa. A atribuição a uma crônica de eventos de uma estrutura-de-enredo, que eu chamo de operação de "enredamento", é feita por meio de técnicas discursivas que são de natureza mais tropológica do que lógica. ${ }^{4}$
\end{abstract}

Parece-me, desta forma, que o empenho de Hayden White em analisar, ao longo de sua obra, aquilo que chama de "forma manifesta" do trabaIho histórico ("uma estrutura verbal na forma de um discurso narrativo em prosa") $)^{5}$ tem grande afinidade com a crítica dos equívocos sobre o binômio "tradição/inovação" realizada por Javier Fernández Sebastián - que, aliás, não deixa de reconhecer que "as impressões de ruptura ou de continuidade são produzidas por meio de diversos recursos literários". E, se é assim, penso que investir mais nesse luminoso ponto de contato entre a história intelectual e o movimento contemporâneo da história da historiografia poderia se configurar como um desdobramento muito fértil da análise aqui discutida.

II

Inspirando-se na crítica de Jörn Rüsen às "tradições inventadas" de Hobsbawm, Javier Fernández Sebastián apresenta, como visto em seu artigo, as "tradições eletivas" como uma forma híbrida, situada entre o tipo "funcional" e o tipo "reflexivo", e "peculiarmente moderna" de tradição; mais precisamente, ele pensa naquelas "tradições que os construtores das grandes ideologias contemporâneas atribuem a seus próprios movimentos sociais ou políticos, que assim aparecem dotados de uma prosápia histórica mais ou menos ilustre". Pode dizer, assim, que este gênero "inverte o sentido da flecha do tempo" - do futuro, e não do passado, para o presente - e, ao fazê-lo, disfarça, senão contrabandeia, sob seu manto muitas vezes tido por sagrado as inovações aceitáveis, desejáveis e/ou necessárias à afirmação de um determinado projeto político, como Fernández Sebastián exemplifica à larga, ou intelectual, como ele mesmo também não deixa de sugerir e, com muita perspicácia, Fernando Nicolazzi aplica à relação entre memória disciplinar e história da historiografia. 
6

HOBSBAWM, Eric. Dentro e fora da História. In: Sobre história: ensaios. São Paulo: Companhia das Letras, 1998. p. 17.

7

Idem, ibidem.

8

Aqui, inspiro-me livremente (e talvez excessivamente) no artigo de KLEINBERG, Ethan. Introduction: the "Trojan horse" of tradition. History and Theory, Middletown, Vol. 51, n. 4, dez./2012. p. 1-5.
A destreza com que Fernández Sebastián trabalha suas referências e apresenta sua concepção de "tradições eletivas" deixa evidente o quão pertinente e poderosa ela pode ser se empregada na tarefa de superar a oposição entre tradição e inovação e, sobretudo, para realçar como estes, "longe de ser termos incompativeis, se entrelaçam e se implicam mutuamente" - e, aqui, ressalto uma vez mais as páginas finais do artigo como exemplares. Mas, isso também me provoca uma inquietação, a qual me leva a perguntar: como essa categoria pode ser metodologicamente manejada pelo historiador no processo de examinar, reconstruir e representar o passado? Ou, dito de modo que espero seja mais claro, como e onde 0 historiador consegue percebê-las e recuperá-las em sua especificidade de tradições eletivas, uma vez que elas se articulam, potencial e efetivamente, com outras categorias, tipos, conceitos de "tradição"? Se pensarmos na classificação elaborada pelo próprio Rüsen, conforme citado por Fernández Sebastián, já não é difícil perceber como as diferentes formas de tradição são permeáveis e intercambiáveis entre si; o problema, contudo, a meu ver é ainda mais complexo, como a citação abaixo pode ajudar a demonstrar:

Eu me lembro de ter visto em algum lugar um estudo sobre a civilização antiga do vale do Indus com o título Cinco mil anos de Paquistão. 0 Paquistão nem mesmo era cogitado antes de 1932-3, quando o nome foi inventado por alguns militantes estudantis. Apenas se tornou uma demanda política séria a partir de 1940. Como Estado apenas existiu a partir de 1947. Não há nenhuma evidência de haver mais conexão entre a civilização de Mohenjo Daro e os atuais governantes de Islamabad que entre a Guerra de Troia e o governo de Ancara, que no momento [1994] reivindica o retorno, ainda que apenas para a primeira exibição pública, do tesouro de Schliemann do rei Priamo de Troia. Mas, de certo modo, 5 mil anos de Paquistão soam melhor do que 46 anos de Paquistão. ${ }^{6}$

0 som que ecoa dessas palavras de Hobsbawm é, obviamente, o da invenção das tradições, e talvez não pudesse ser diferente. Todavia, não podemos ouvir ai também a reverberação das tradições eletivas de Fernández Sebastián, à medida que se trata de um exemplo de justificativa ideológica de algo que "não é antigo ou eterno, mas historicamente novo"?? Se, neste e em tantos outros incontáveis casos, a apropriação e o uso político do passado elegem, selecionam, reordenam aquilo que interessa em função de algo que não existia antes, criando uma história "prêt-à-porter", destinada a atender demandas presentes ou futuras, parece-me que, em termos práticos, a distinção entre tradição eletiva e tradição inventada (ou entre quaisquer outras formas "ideais" de tradição) não é, ao fim e ao cabo, tão marcante, sequer mesmo tão crucial; crucial mesmo é observar como o apelo à tradição - que não é a mesma coisa que "a tradição" - muitas vezes, senão sempre, funciona como um cavalo de Troia, escondendo em seu ventre oco, pelos mais diferentes propósitos, os elementos da mudança e da inovação. ${ }^{8}$

\section{III}

É desnecessário dizer que os comentários muito gerais aqui apresentados não contestam, sequer abalam, o sucesso de Javier Fernández Sebastián em mostrar as "poliédricas relações entre modernidade e tradição", bem como em demonstrar como a história intelectual vem dando conta da tarefa que não deixa de ser também um desafio - de desativar os "endiabrados mecanismos" que a perpassam. Minha última rápida observação, assim, 
intenta apenas ressaltar a relevância do debate no qual ele se insere e, com isso, a pertinência de um programa de pesquisa que articule a história dos conceitos, a história da historiografia e a história das práticas discursivas, como proposto ao final do artigo.

Como visto, ao mesmo tempo em que se empenha em demonstrar o quão empobrecedoras são as visões dicotômicas das relações entre tradição e inovação, tanto na historiografia em geral quanto na história intelectual em particular, Fernández Sebastián também ora sugere, ora afirma com todas as letras, que hoje imperam na história intelectual "visões muito mais férteis e refinadas" para dar conta de tais relações - basicamente, a Begriffsgeschichte koselleckiana e o contextualismo skinneriano. Pois bem: sabendo-se que o "hoje", no caso, envolve as últimas duas ou três décadas de debates nesse campo, senão mais, talvez fosse natural perguntar a quem, no presente, se dirige essa crítica, uma vez que, se "a velha história das ideias" já pode ser assim nomeada sem hesitação, de qual "novidade" se está falando, exatamente? Atento ao potencial problema, Fernández Sebastián dele não se esquiva:

Junto a estas dos aproximaciones [de Koselleck e Skinner] y a los instrumentos de conocimiento e interpretación de las formaciones político-intelectuales del pasado a ellas asociadas (y también a otras aproximaciones más recientes, como el análisis histórico-morfológico propuesto por Michael Freeden), el enfoque de las "tradiciones electivas" que he defendido en este trabajo podría arrojar luz sobre determinados aspectos de la historia de las ideologías y de los movimientos políticos y sociales en los últimos siglos. Me refiero a aspectos que quedan en sombra, o no se perciben suficientemente, desde las mencionadas perspectivas (y resultan completamente opacados desde las ópticas más tradicionales de la historia de las ideas o de la filosofia política).

Tais afirmações deixam claro que Javier Fernández Sebastián pretende ir além não apenas do "velho", mas também do "estabelecido" no campo da história intelectual. E ainda que o enfoque pelo viés das "tradições eletivas" possa ser criticado, como tentei fazê-lo aqui, é inegável que ele representa uma tentativa - muito sugestiva e poderosa, não custa nada repetir - de avanço e inovação na abordagem tanto de conceitos e discursos políticos quanto do próprio passado. Nesse sentido, colocando-se contra os reducionismos, os mecanicismos, as fórmulas fáceis e/ou consagradas (muitas vezes consagradas porque fáceis), seu artigo nos oferece também um belo exemplo de como se pensar tanto o "mundo das ideias" quanto, sobretudo, a produção a seu respeito. 